Research Paper

\title{
Evolution of COVID-19 in patients with autoimmune rheumatic
}

\section{diseases}

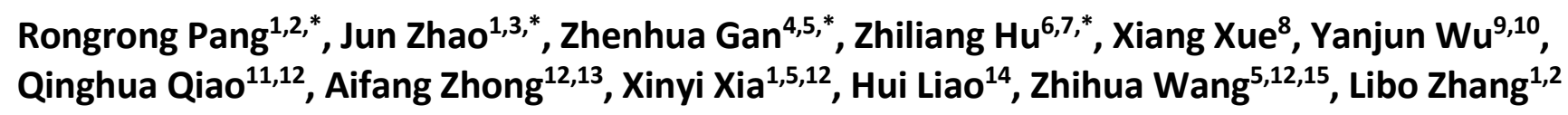

${ }^{1}$ COVID-19 Research Center, Institute of Laboratory Medicine, Jinling Hospital, Nanjing University School of Medicine, The First School of Clinical Medicine, Southern Medical University, Nanjing 210002, Jiangsu, China ${ }^{2}$ Department of Laboratory Medicine, Nanjing Red Cross Blood Center, Nanjing 210003, Jiangsu, China

${ }^{3}$ Graduate School, Nanjing Medical University, Nanjing 211166, Jiangsu, China

${ }^{4}$ Department of Medical Administration, Jinling Hospital, Nanjing University School of Medicine, Nanjing 210002, China

${ }^{5}$ Joint Expert Group, Wuhan Huoshenshan Hospital, Wuhan 430100, Hubei, China

${ }^{6}$ Nanjing Infectious Disease Center, The Second Hospital of Nanjing, Nanjing University of Chinese Medicine, Nanjing 210003, Jiangsu, China

${ }^{7}$ School of Public Health, Nanjing Medical University, Nanjing 211166, Jiangsu, China

${ }^{8}$ Department of Biochemistry and Molecular Biology, University of New Mexico, Albuquerque, NM 87131, USA

${ }^{9}$ Department of Information, Jinling Hospital, Nanjing University School of Medicine, Nanjing 210002, China

${ }^{10}$ Department of Information, Wuhan Huoshenshan Hospital, Wuhan 430100, Hubei, China

${ }^{11}$ Medical and Technical Support Department, Pingdingshan Medical District, The 989th Hospital, Pingdingshan 467000, Henan, China

${ }^{12}$ Department of Laboratory Medicine and Blood Transfusion, Wuhan Huoshenshan Hospital, Wuhan 430100, Hubei, China

${ }^{13}$ Medical Technical Support Division, Changzhou Medical District, The 904th Hospital, Changzhou 213003, Jiangsu, China

${ }^{14}$ Department of Hematology, The Air Force Hospital from Eastern Theater of PLA, Nanjing 210002, Jiangsu, China

${ }^{15}$ Department of Laboratory Medicine and Blood Transfusion, The 907th Hospital, Nanping 350702, Fujian, China

*Equal contribution

Correspondence to: Libo Zhang, Zhihua Wang, Hui Liao, Xinyi Xia; email: 37280240@qq.com, https://orcid.org/0000-00022972-5174; sunnywzh77@163.com, https://orcid.org/0000-0002-8658-4697; Ih@454hosp.cn; xinyixia@nju.edu.cn

Keywords: coronavirus disease 2019, SARS-CoV-2 virus, autoimmune rheumatic diseases, systematic lupus erythematosus, rheumatoid arthritis

Received: May 15, 2020

Accepted: October 20, 2020

Published: December 03, 2020

Copyright: (C) 2020 Pang et al. This is an open access article distributed under the terms of the Creative Commons Attribution License (CC BY 3.0), which permits unrestricted use, distribution, and reproduction in any medium, provided the original author and source are credited.

\section{ABSTRACT}

The characteristics of COVID-19 patients with autoimmune rheumatic diseases (AIRD) have rarely been reported. Patients with AIRD have suppressed immune defense function, which may increase their susceptibility to COVID-19. However, the immunosuppressive agents AIRD patients routinely used may be beneficial for protecting the cytokine storm caused by SARS-CoV-2. In this retrospective study, we included all confirmed cases in Huoshenshan Hospital from February 4 to April 9. Data were extracted from electronic medical records and were analyzed for clinical and laboratory features using SPSS (version 25.0). Of 3059 patients, 21 had the comorbidities with systematic lupus erythematosus (SLE) and/or rheumatoid arthritis (RA), including 5 with SLE, 15 with RA, and 1 with Rhupus. The proportion was $57.1 \%$ for severe cases, $61.9 \%$ for 
either severe or critical cases, and $4.8 \%$ for critical cases. The main manifestations, ARDS and ICU admission rate, as well as the mortality and length of hospital stay of COVID-19 in AIRD patients were similar to COVID-19 patients in the general population. Our preliminary experience shows that patients with AIRD tend to have a higher risk of SARS-CoV-2 infection, and may be at risk for a severe but less likely critical disease course. Further investigation is needed to understand the immunological features of these diseases.

\section{INTRODUCTION}

Currently we are on a global pandemic of coronavirus disease-2019 (COVID-19). Up till today, no pharmacological therapies have been proven efficacy yet. The main treatments are supportive therapies, including fluid management, oxygen supply and extracorporeal membrane oxygenation. Accordingly, the resolution and recovery rely heavily on the host's immunity.

However, the host immunity acts like a double-edge sword during the response to the new coronavirus: it may provide a strong immunological response adequate for virus clearance, while on the other hand, excessive proinflammatory cytokines induced by the uncontrolled immune response with features of cytokine storm may cause a severe disease course and then worsen the prognosis of COVID-19 [1-4].

People with autoimmune rheumatic diseases (AIRD), such as systematic lupus erythematosus (SLE) and rheumatoid arthritis (RA), were inferred to have an increased risk of SARS-CoV-2 infection due to suppressed immune defense function by the illness per se or the therapy, since precedent studies reported that immune suppression delayed viral clearance and increased rates of secondary infections in SARS and MERS outbreaks [5, 6].

Nonetheless, it remains controversial that whether individuals with immunosuppression are more susceptible of or protective from SARS-CoV-2 infection. A previous study showed lack of symptomatic infection with SARS-CoV-2 in children treated with immunomodulatory and immunosuppressive treatment [7]. Similar findings in a cohort of liver transplant patients reported a low rate (3 out of 200) of SARS-CoV-2 infections [8]. However, to date, little evidence-based data were available to describe the clinical and immunological features of AIRD in COVID-19 patients.

As a result, concerns have arisen about the characteristics, diagnosis, treatment and monitoring of certain diseases. Here we describe the clinical characteristics, laboratory findings and outcome of 21 COVID-19 patients underlying comorbidities with AIRD from Huoshenshan Hospital.

\section{RESULTS}

\section{Baseline characteristics and laboratory findings}

The underlying autoimmune diseases in this study contained 5 cases of SLE, 15 cases of RA and 1 case of Rhupus. Twenty (95.2\%) patients were female. The median age was 62 years old (50.5-66.5). Totally, fourteen $(66.7 \%)$ patients had other comorbidities (Table 1). Five patients had more than two kinds of comorbidities, in which $4(80 \%)$ cases were either severe or critical illness. While in the 16 cases who had no more than one comorbidity, only $6(37.5 \%)$ patients developed severe illness.

The median time from symptoms onset to admission was 25 (14-30) days. At the time of admission, 90.5\% (19/21) presented with fever, with the highest temperature of $39.8^{\circ}$ C. $71.4 \%(15 / 21)$ had cough; $38.1 \%(8 / 21)$ had chills; $19.0 \%$ (4/21) had sputum; $42.8 \%(9 / 21)$ had shortness of breath; $66.7 \%(14 / 21)$ had myalgia; $14.3 \%$ (3/21) patients had chest pain, and nausea was found in $61.9 \%(13 / 21)$ patients.

Laboratory results showed that $60 \%$ of the patients with SLE, $33.3 \%$ with RA and the only one Rhupus patient developed lymphopenia, while $28.6 \%$ (6/21) had lymphopenia at entry. The median level of lymphocyte counts at entry was $1.41 \times 10^{9} / \mathrm{L}$. C-reactive protein was significantly increased in $80 \%$ SLE patients and $40 \%$ RA patients, as well as the Rhupus patient. In addition, elevated PCT and IL-6 were also demonstrated among the patients in a certain proportion (Table 2).

\section{Treatment}

The main treatments included supportive therapy, antibiotic and antiviral therapy, as well as immunotherapy. The antiviral regimen mainly included interferon-alpha (5 million $U$ atomized twice daily), arbidol (200mg three times a day orally, for no more than 10 days), lopinavir/ritonavir $(400 \mathrm{mg} / 100 \mathrm{mg}$ twice daily, for no more than 10 days), and the traditional Chinese medicine such as Lianhuaqingwen capsule was also employed depends on the actual situation of the patient. Convalescent plasma therapy was suitable for severe and critical patients with rapid progression. 
Table 1. Comorbidities of patients with AIRD infected with SARS-CoV-2f.

\begin{tabular}{|c|c|c|c|c|}
\hline \multirow{2}{*}{ Characteristics } & \multicolumn{3}{|c|}{ Types of AIRD } & \multirow{2}{*}{$\begin{array}{c}\text { Total } \\
(n=21)\end{array}$} \\
\hline & SLE $(n=5)$ & RA $(n=15)$ & Rhupus (n=1) & \\
\hline Female, n (\%) & $4(80)$ & $15(100)$ & $1(100)$ & $20(95.2)$ \\
\hline Age, years, median (IQR) & $48(35-52)$ & $64(58-68)$ & 66 & $62(50.5-66.5)$ \\
\hline \multicolumn{5}{|l|}{ Comorbidities } \\
\hline Pre-existing pulmonary diseases ${ }^{\mathrm{a}}, \mathrm{n}(\%)$ & $0(0)$ & $0(0)$ & $1(100)$ & $1(4.8)$ \\
\hline Cardiovascular and cerebrovascular diseases ${ }^{\mathrm{b}}, \mathrm{n}(\%)$ & $4(80)$ & $3(20)$ & $0(0)$ & $7(33.3)$ \\
\hline Diabetes, n (\%) & $0(0)$ & $2(13.3)$ & $1(100)$ & $3(14.3)$ \\
\hline Kidney diseases ${ }^{\mathrm{c}}, \mathrm{n}(\%)$ & $2(40)$ & $1(6.7)$ & $1(100)$ & $4(19.0)$ \\
\hline Hypothyroidism, n (\%) & $2(40)$ & $0(0)$ & $0(0)$ & $2(9.5)$ \\
\hline Tumors $^{\mathrm{d}}, \mathrm{n}(\%)$ & $1(20)$ & $0(0)$ & $0(0)$ & $1(4.8)$ \\
\hline Other comorbidities ${ }^{\mathrm{e}}, \mathrm{n}(\%)$ & $3(60)$ & $4(26.6)$ & $1(100)$ & $8(38.1)$ \\
\hline
\end{tabular}

aThe only Rhupus patient had a pre-existing pulmonary disease of bronchiectasis with infection.

${ }^{b}$ Cardiovascular and cerebrovascular diseases included primary or secondary hypertension, coronary atherosclerosis, lacunar infarction, uremic cardiomyopathy, post congenital heart surgery, and pericardial effusion.

'Kidney diseases included primary or secondary nephritis and chronic kidney disease.

${ }^{\mathrm{d} O n e}$ patient with SLE had an adrenal tumor.

eOther comorbidities included primary or secondary anemia, hypoproteinemia, hyponatremia, gout or hyperuricemia, thrombocytopenia, disorders of electrolyte metabolism, pleural or abdominal effusion, chronic pharyngitis, stomach ulcer, gallstone and multiple organ failure.

fData were expressed as number (percentage) and median (interquartile range).

Patients with SLE and Rhupus remained on immunomodulatory or immunosuppressive therapy in order to control their underlying rheumatic conditions. Corticosteroids were administrated to 6 patients during their hospitalization, one patient received intravenous immunoglobulin treatment, and three patients recovered under the therapy of convalescent plasma transfusion.

During their hospitalization, two patients of SLE remained in stable condition. One patient of SLE had hydrothorax and pericardial effusion revealed by CT. Thus she was treated with a decreased dose of prednisone acetate tablets (30mg to $20 \mathrm{mg}$ ). Another patient was treated with an increased dose of methylprednisolone (from $40 \mathrm{mg}$ to $60 \mathrm{mg}$ per day, intravenous) due to a relapse of SLE, but withhold unchanged dose of immunosuppressant therapy. One patient with RA was given prednisone acetate tablets (20mg, once daily, orally) for her elevated CRP and an underlying inflammatory process revealed by radiology, while another RA patient was administrated with prednisone tablets at a dose of $10 \mathrm{mg}$ orally because of a worsened pain of her lower extremity joint. However, none of the patients presented definite worsening or exacerbation of the pre-existed autoimmune diseases secondary to COVID-19.

\section{Severity and outcome of patients with AIRD infected with SARS-CoV-2}

Table 3 shows the severity and outcome markers of the study subjects. Approximately $57.1 \%$ (12/21) AIRD subjects were classified as severe cases, while $61.9 \%$ $(13 / 21)$ as either severe or critical cases. In terms of critical cases, the proportion was $4.8 \%(1 / 21)$ in the AIRD population.

Twenty patients have recovered and been discharged from hospital with a median hospital stay of 13.5 (8.25 - 20.25) days and median illness course of 42 (33.75 - 52.5) days. Only one patient developed acute 
respiratory distress syndrome (ARDS), and unfortunately the patients eventually died. He was a 25-year-old man with obesity and complex underlying comorbidities including lupus nephritis, chronic kidney disease, renal hypertension, renal anemia, uremic cardiomyopathy, and post congenital heart sur- gery, and he had long term self-medication with immunosuppressant such as prednisone and leflunomide for treating SLE. He subsequently died with multiorgan failure, and cardiopulmonary arrest on day 9 of hospitalization, despite aggressive supportive care and investigational therapies.

Table 2. Clinical characteristics, treatment, outcome and laboratory findings of patients with AIRD infected with SARS-CoV-2 ${ }^{\mathrm{a}}$.

\begin{tabular}{|c|c|c|c|c|}
\hline \multirow{2}{*}{ Characteristics } & \multicolumn{3}{|c|}{ Types of AIRD } & \multirow{2}{*}{$\begin{array}{l}\text { Total } \\
(n=21)\end{array}$} \\
\hline & SLE $(n=5)$ & $\mathbf{R A}(\mathbf{n}=\mathbf{1 5})$ & Rhupus (n=1) & \\
\hline \multicolumn{5}{|l|}{ Clinical characteristics } \\
\hline Temperature on admission, ${ }^{\circ} \mathrm{C}$, median (IQR) & $39.0(38.4-39.2)$ & $38.0(37.8-39.0)$ & 38.2 & $37.9(38.5-39.0)$ \\
\hline Respiratory rate, median (IQR) & $22(20-22.5)$ & $20(19-21)$ & 20 & $20(20-22)$ \\
\hline Pulse, median (IQR) & $101(91-106.5)$ & $84(76-100)$ & 80 & $92(76-101.5)$ \\
\hline Fever, $\mathrm{n}(\%)$ & $5(100)$ & 13(86.6) & $1(100)$ & $19(90.5)$ \\
\hline Cough, $\mathrm{n}(\%)$ & $3(60)$ & $11(73.3)$ & $1(100)$ & $15(71.4)$ \\
\hline Chills, n(\%) & $2(40)$ & $6(40)$ & $0(0)$ & $8(38.1)$ \\
\hline Sputum, n(\%) & $1(20)$ & $2(33.3)$ & $1(100)$ & $7(33.3)$ \\
\hline Shortness of breath, n(\%) & $2(40)$ & $6(40)$ & $1(100)$ & $9(42.9)$ \\
\hline Myalgia, n(\%) & $2(40)$ & $11(73.3)$ & $1(100)$ & $14(66.7)$ \\
\hline Chest pain, n(\%) & 1(20) & $1(6.6)$ & $1(100)$ & $3(14.3)$ \\
\hline Nausea, $\mathrm{n}(\%)$ & $2(40)$ & $10(66.6)$ & $1(100)$ & 13(61.9) \\
\hline \multicolumn{5}{|l|}{ Treatment of COVID-19 } \\
\hline Oxygen support, n(\%) & $2(40)$ & $4(80)$ & $1(100)$ & $7(33.3)$ \\
\hline Invasive mechanical ventilation, $\mathrm{n}(\%)$ & $0(0)$ & $0(0)$ & $0(0)$ & $0(0)$ \\
\hline Interferon, $\mathrm{n}(\%)$ & $1(20)$ & $2(33.3)$ & $0(0)$ & $3(14.3)$ \\
\hline Arbidol Hydrochloride Capsules, $\mathrm{n}(\%)$ & $2(40)$ & $10(66.6)$ & $1(100)$ & 13(61.9) \\
\hline Oseltamivir, $\mathrm{n}(\%)$ & $0(0)$ & $2(33.3)$ & $0(0)$ & $2(9.5)$ \\
\hline Thymalfasin, $\mathrm{n}(\%)$ & $0(0)$ & $3(20)$ & $0(0)$ & $3(14.3)$ \\
\hline Lianhuaqingwen capsule, $\mathrm{n}(\%)$ & $1(20)$ & $10(66.6)$ & $0(0)$ & $11(52.4)$ \\
\hline Other Chinese herbal medicines, $\mathrm{n}(\%)$ & $1(20)$ & $1(6.6)$ & $0(0)$ & $2(9.5)$ \\
\hline IVIG treatment, $\mathrm{n}(\%)$ & $1(20)$ & $0(0)$ & $0(0)$ & $1(4.8)$ \\
\hline CPT treatment, $\mathrm{n}(\%)$ & $2(40)$ & $0(0)$ & $0(0)$ & $2(9.5)$ \\
\hline
\end{tabular}


Antibiotic treatment, $\mathrm{n}(\%)$

Treatment of autoimmune diseases

Corticosteroid treatment during hospitalization, $\mathrm{n}(\%)$

Long-term Corticosteroid treatment, n(\%)

Hydroxychloroquine treatment, $\mathrm{n}(\%)$

Cyclosporin A, n(\%)

Mycophenolate Mofetil, n(\%)

\section{Outcome of COVID-19}

Discharged, n(\%)

Hospital stay, days, median (IQR) ${ }^{\#}$

Onset to discharge, days, median (IQR) ${ }^{\#}$

Died, $\mathrm{n}(\%)$

\section{Laboratory findings}

Lymphocyte counts at entry, $\times 10^{9} / \mathrm{L}$, median (IQR)

Lymphopenia, n(\%)

High CRP, n(\%)

High PCT, n(\%)

High IL-6, n(\%)

Low $\mathrm{C} 3, \mathrm{n}(\%)$
4(80)

$10(8-17)$

3(60)

$8(53.3)$

$1(100)$

$12(57.1)$

$\begin{array}{lccc}2(40) & 3(20) & 1(100) & 6(28.6) \\ 5(100) & 1(6.6) & 1(100) & 7(33.3) \\ 4(80) & 1(6.6) & 1(100) & 6(28.6) \\ 1(20) & 0(0) & 0(0) & 1(4.8) \\ 1(20) & 0(0) & 0(0) & 1(4.8)\end{array}$

22(15.5-57)

$42(36-53)$

$0(0)$

"Excluding the deceased patient.

${ }^{a}$ Data were expressed as number (percentage) and median (interquartile range).

\section{Table 3. Severity and outcomes of patients with AIRDa}

\section{Subjects with AIRD (n=21)}

Severe cases, n(\%)

Severe or critical cases, $\mathrm{n}(\%)$

Critical cases, $\mathrm{n}(\%)$

Length of hospital stay, days, median (IQR)

Developing ARDS, n(\%)

Admission to ICU, $\mathrm{n}(\%)$

Mortality, n(\%)

$\begin{array}{cccc}1.23(0.62-1.46) & 1.49(1.09-1.58) & 1.77 & 1.41(1.04-1.58) \\ 3(60) & 5(33.3) & 1(100) & 9(42.8) \\ 4(80) & 6(40) & 1(100) & 11(52.4) \\ 3(60) & 3(20) & 1(100) & 7(33.3) \\ 3(60) & 4(26.6) & 0(0) & 7(33.3) \\ 3(20) & 0(0) & 0(0) & 3(14.3)\end{array}$

$13(61.9 \%)$

$1(4.8 \%)$

$13.5(7-37)$

$1(4.8 \%)$

$0(0 \%)$

$1(4.8 \%)$

${ }^{a}$ Data were expressed as number (percentage) and median (interquartile range). 


\section{DISCUSSION}

We report the clinical characteristics, laboratory findings and outcomes of 21 COVID-19 patients who have comorbidities with SLE and/or RA. Fever, cough, and nausea were observed in most of the patients, which was similar to the manifestation of COVID-19 in the general population $[9,10]$. Notwithstanding, it provides us a picture of the characteristics and course of these patients.

A previous study has reported that immunosuppressed subjects may have an increased risk of SARS-CoV-2 infection [11]. In our hospital, five (163 per 100,000) and fifteen $(490$ per 100,000$)$ patients had a history of SLE and RA, respectively, meanwhile one patient (32.69 per 100,000) had both the symptoms of SLE and RA. The prevalence was remarkably higher than that in the general population (27-70 per 100,000 for SLE, 280 per 100,000 for RA, respectively) [12-15], indicating that AIRD patients might have an increased risk of SARS-CoV-2 infection.

Comorbidities such as hypertension and diabetes are recognized as important factors in patients with COVID-19. Our study demonstrated that patients who had multiple comorbidities were seen to have a higher severity of COVID-19. Thus, more varieties of comorbidities were also associated with increased severity in the AIRD group of patients, similar to the general population $[16,17]$.

In AIRD related patients, the proportion of severe cases(57.1\%) was relatively higher than the general population(11.4-15.74\%) [18, 19], as well as in either severe or critical cases $(61.9 \%$ vs. $19 \%)$, whereas it was lower in critical cases $(4.9 \%$ vs. $5 \%)$. We proposed that in the early phase, the patients may be prone to more severe infection due to their impaired immune function, which was not adequate for virus clearance. While in the late phase, it is plausible that some immunosuppressive agents routinely used for rheumatological therapy might offer an advantage on the aberrant inflammatory and cytokine response perpetuated by the host immune system, preventing the patients from developing critical illness.

However, our study had several limitations. Firstly, we had a small sample size, which might reflect a local experience. Secondly, outcomes were likely to be mixed depending on factors such as different types and disease activity of AIRD, and also combinations of therapies [7, 20-22]. AIRD patients with COVID19 are a great challenge for the physicians to achieve personalized treatment programs both effective for COVID-19 and their underlying rheumatic conditions. A striking interplay between infection, inflammation, and immunological pathogenetic mechanisms in COVID-19 patients with AIRD needs to be further studied. Thirdly, the role of anti-rheumatic medications is an ongoing area of interest [23-25]. Drugs including hydroxychloroquine (HCQ), chloroquine (CQ) and glucocorticoids theoretically have potential associations with the severity of COVID-19. However, due to limitations imposed by the small sample size, our data are not sufficient to draw the conclusion whether current treatment for AIRD is a risk or not for severe forms of evolution. There is a need for wellconducted and large population-based studies to ascertain the role of specific rheumatic treatments in the evolution of COVID-19.

In the present work, we retrospectively analyzed the clinical features, laboratory findings and outcomes of 21 COVID-19 confirmed patients accompanying AIRD, and our preliminary experience shows that patients with AIRD tend to have a higher risk of SARS-CoV-2 infection, and may be at risk for a severe but less likely critical disease course.

\section{MATERIALS AND METHODS}

\section{Study design}

This study included 21 COVID-19 patients with underlying autoimmune diseases, who were admitted to the Huoshenshan Hospital, Wuhan, China, from February 4, 2020, to April 9, 2020. The demographic data, medical history, underlying diseases, symptoms, signs, blood laboratory parameters, treatments and outcomes were collected from the electronic health record system and were retrospectively analyzed. The comorbidities evaluated in the study included pre-existing pulmonary diseases, cardiovascular and cerebrovascular diseases, diabetes, kidney diseases, thyroid diseases and tumors. This study was approved by the Medical Ethical Committee of Huoshenshan Hospital with participants' written informed consent (HSSLL011).

\section{Severity of COVID-19}

Severe disease was defined by one or more of the following conditions: (1)Shortness of breath, RR $\geq$ 30 times/min; (2)In the resting state, the oxygen saturation is less than or equal to 93\%; (3)Arterial oxygen partial pressure $\left(\mathrm{PaO}_{2}\right)$ /oxygen inhalation concentration $\left(\mathrm{FiO}_{2}\right) \leq 300 \mathrm{mmHg}$; (4)Pulmonary imaging shows that patients with obvious lesion progression $>50 \%$ within $24-48$ hours. 
The critical disease was defined by one or more of the following conditions: (1) Respiratory failure occurs, and mechanical ventilation is required; (2) Shock; (3) ICU monitoring and treatment are required for other organ failures.

\section{Statistical analysis}

Continuous variables were summarized as median with interquartile range; categorical variables were summarized as counts and percentages. Data were extracted from electronic medical records and were analyzed for clinical and laboratory features using SPSS (version 25.0).

\section{Disclosure statement}

There are no potential conflicts of interest relevant to this article to report.

\section{Abbreviations}

COVID-19: coronavirus disease 2019; SLE: systematic lupus erythematosus; RA: rheumatoid arthritis; ICU: Intensive Care Unit; ARDS: acute respiratory distress syndrome; CPT: convalescent plasma therapy; HCQ: hydroxychloroquine; CQ: chloroquine.

\section{AUTHOR CONTRIBUTIONS}

R.R.P. and J.Z. conducted data analysis and wrote the paper. Z.H.G. and Z.L.H. participated in the design of the study. X.X., Y.J.W., Q.H.Q. and A.F.Z. contributed with comments during the writing. X.Y.X. conceived the study. H.L. and Z.H.W. collected the data. L.B.Z participated in the design and conducted data analysis. All authors read and approved the final manuscript.

\section{ACKNOWLEDGMENTS}

We gratefully acknowledge the intense individual effort and support from many sources to make this study possible and the contributions of plasma donors.

\section{CONFLICTS OF INTEREST}

The authors declare that they have no conflicts of interest.

\section{FUNDING}

This study was supported by Key Foundation of Wuhan Huoshenshan Hospital (2020 [18]), Key Research and Development Program of Jiangsu Province(BE2018713), Medical Innovation Project of Logistics Service (18JS005), The Foundation of Jiangsu Population
Association (JSPA2019017), Medical Science and technology development Foundation, Nanjing Department of Health (ZDX16019), and InTec Scientific Research Fund of Jiangsu Blood Transfusion Association (js2018034). Dr. Xiang Xue is supported by the National Institutes of Health (K01DK114390, P20 GM130422) and a Research Scholar Grant from the American Cancer Society (RSG-18-050-01-NEC).

\section{REFERENCES}

1. Mehta P, McAuley DF, Brown M, Sanchez E, Tattersall RS, Manson JJ, and HLH Across Speciality Collaboration, UK. COVID-19: consider cytokine storm syndromes and immunosuppression. Lancet. 2020; 395:1033-34. https://doi.org/10.1016/S0140-6736(20)30628-0 PMID: $\underline{32192578}$

2. Vaninov N. In the eye of the COVID-19 cytokine storm. Nat Rev Immunol. 2020; 20:277.

https://doi.org/10.1038/s41577-020-0305-6 PMID: $\underline{32249847}$

3. Ye $Q$, Wang $B$, Mao J. The pathogenesis and treatment of the 'Cytokine storm' in COVID-19. J Infect. 2020; 80:607-13.

https://doi.org/10.1016/j.jinf.2020.03.037 PMID:32283152

4. Zhang C, Wu Z, Li JW, Zhao H, Wang GQ. Cytokine release syndrome in severe COVID-19: interleukin-6 receptor antagonist tocilizumab may be the key to reduce mortality. Int J Antimicrob Agents. 2020; 55:105954.

https://doi.org/10.1016/j.ijantimicag.2020.105954 PMID:32234467

5. Auyeung TW, Lee JS, Lai WK, Choi $\mathrm{CH}$, Lee HK, Lee JS, Li PC, Lok KH, Ng YY, Wong WM, Yeung YM. The use of corticosteroid as treatment in SARS was associated with adverse outcomes: a retrospective cohort study. J Infect. 2005; 51:98-102.

https://doi.org/10.1016/i.jinf.2004.09.008 PMID:16038758

6. Hui DS. Systemic corticosteroid therapy may delay viral clearance in patients with middle east respiratory syndrome coronavirus infection. Am J Respir Crit Care Med. 2018; 197:700-01.

https://doi.org/10.1164/rccm.201712-2371ED PMID:29227752

7. Cron RQ, Chatham WW. The question of whether to remain on therapy for chronic rheumatic diseases in the setting of the covid-19 pandemic. J Rheumatol. 2020. [Epub ahead of print]. https://doi.org/10.3899/jrheum.200492 PMID:32335514 
8. D’Antiga L. Coronaviruses and immunosuppressed patients: the facts during the third epidemic. Liver Transpl. 2020; 26:832-34.

https://doi.org/10.1002/lt.25756

PMID:32196933

9 Li LQ, Huang T, Wang YQ, Wang ZP, Liang $Y$, Huang TB, Zhang HY, Sun W, Wang Y. COVID-19 patients' clinical characteristics, discharge rate, and fatality rate of meta-analysis. J Med Virol. 2020; 92:577-583.

https://doi.org/10.1002/jmv.25757

PMID:32162702

10. Tian S, Hu N, Lou J, Chen K, Kang X, Xiang Z, Chen H, Wang D, Liu N, Liu D, Chen G, Zhang Y, Li D, et al. Characteristics of COVID-19 infection in Beijing. J Infect. 2020; 80:401-06.

https://doi.org/10.1016/i.jinf.2020.02.018

PMID: $\underline{32112886}$

11. Banerjee D, Popoola J, Shah S, Ster IC, Quan V, Phanish M. COVID-19 infection in kidney transplant recipients. Kidney Int. 2020; 97:1076-82.

https://doi.org/10.1016/i.kint.2020.03.018 PMID:32354637

12. Dai SM, Han XH, Zhao DB, Shi YQ, Liu Y, Meng JM. Prevalence of rheumatic symptoms, rheumatoid arthritis, ankylosing spondylitis, and gout in Shanghai, China: a COPCORD study. J Rheumatol. 2003; 30:2245-51.

PMID:14528524

13. Osio-Salido E, Manapat-Reyes H. Epidemiology of systemic lupus erythematosus in Asia. Lupus. 2010; 19:1365-73.

https://doi.org/10.1177/0961203310374305

PMID:20947544

14. Zeng QY, Chen R, Darmawan J, Xiao ZY, Chen SB, Wigley R, Le Chen S, Zhang NZ. Rheumatic diseases in China. Arthritis Res Ther. 2008; 10:R17.

https://doi.org/10.1186/ar2368

PMID:18237382

15. Zou YF, Feng CC, Zhu JM, Tao JH, Chen GM, Ye QL, Cen $H$, Leng RX, Pan FM, Pan HF, Li R, Fan YG, Wang B, et al. Prevalence of systemic lupus erythematosus and risk factors in rural areas of Anhui Province. Rheumatol Int. 2014; 34:347-56.

https://doi.org/10.1007/s00296-013-2902-1 PMID:24264010

16. Sepulchre E, Pittie G, Stojkovic V, Haesbroek G, Crama $\mathrm{Y}$, Schyns M, Paridaens H, de Marchin J, Degesves S, Biemar C, Boccar S, Senterre JM, Minon JM. Covid-19: contribution of clinical characteristics and laboratory features for early detection of patients with high risk of severe evolution. Acta Clin Belg. 2020. [Epub ahead of print]. https://doi.org/10.1080/17843286.2020.1822078 PMID:32935644

17. Ahrenfeldt $\amalg$, Nielsen CR, Möller S, Christensen K, Lindahl-Jacobsen R. Burden and prevalence of risk factors for severe COVID-19 disease in the ageing European population - A SHARE-based analysis. Res Sq. 2020. [Epub ahead of print].

https://doi.org/10.21203/rs.3.rs-73657/v1 PMID:32935092

18. Guan WJ, Ni ZY, Hu Y, Liang WH, Ou CQ, He JX, Liu L, Shan H, Lei CL, Hui DS, Du B, Li LJ, Zeng G, et al, and China Medical Treatment Expert Group for Covid-19. Clinical characteristics of coronavirus disease 2019 in China. N Engl J Med. 2020; 382:1708-20.

https://doi.org/10.1056/NEJMoa2002032 PMID:32109013

19. Wu Z, McGoogan JM. Characteristics of and important lessons from the coronavirus disease 2019 (COVID-19) outbreak in China: summary of a report of 72314 cases from the Chinese center for disease control and prevention. JAMA. 2020; 323:1239-42. https://doi.org/10.1001/jama.2020.2648 PMID:32091533

20. Horisberger A, Moi L, Ribi C, Comte D. Impact of COVID-19 pandemic on SLE: beyond the risk of infection. Lupus Sci Med. 2020; 7:e000408.

https://doi.org/10.1136/lupus-2020-000408 PMID:32376774

21. Mathian A, Mahevas M, Rohmer J, Roumier M, CohenAubart F, Amador-Borrero B, Barrelet A, Chauvet C, Chazal T, Delahousse M, Devaux M, Euvrard R, Fadlallah $J$, et al. Clinical course of coronavirus disease 2019 (COVID-19) in a series of 17 patients with systemic lupus erythematosus under long-term treatment with hydroxychloroquine. Ann Rheum Dis. 2020; 79:837-39. PMID: $\underline{32332072}$

22. Tufan A, Avanoğlu Güler A, Matucci-Cerinic M. COVID19 , immune system response, hyperinflammation and repurposing antirheumatic drugs. Turk J Med Sci. 2020; 50:620-32.

https://doi.org/10.3906/sag-2004-168 PMID:32299202

23. Gianfrancesco $\mathrm{M}$, Hyrich $\mathrm{KL}$, Al-Adely $\mathrm{S}$, Carmona $\mathrm{L}$, Danila MI, Gossec L, Izadi Z, Jacobsohn L, Katz P, Lawson-Tovey S, Mateus EF, Rush S, Schmajuk G, et al, and COVID-19 Global Rheumatology Alliance. Characteristics associated with hospitalisation for COVID-19 in people with rheumatic disease: data from the COVID-19 global rheumatology alliance physicianreported registry. Ann Rheum Dis. 2020; 79:859-66. https://doi.org/10.1136/annrheumdis-2020-217871 PMID:32471903 
24. Gomides A, Ferreira G, Kakehasi A, Lacerda M, Marques C, Mota L, Paiva E, Pileggi G, Provenza J, ReisNeto $E$, Sampaio V, Xavier R, Pinheiro M. Impact of Chronic Use of Antimalarials on SARS-CoV-2 Infection in Patients With Immune-Mediated Rheumatic Diseases: Protocol for a Multicentric Observational Cohort Study. JMIR Res Protoc. 2020; 9:e23532.

https://doi.org/10.2196/23532

PMID:32924956

25. Kilian A, Chock YP, Huang IJ, Graef ER, Upton LA, Khilnani A, Krupnikova SD, Almaghlouth I, Cappelli LC, Fernandez-Ruiz R, Frankel BA, Frankovich J, Harrison C, et al. Acute respiratory viral adverse events during use of antirheumatic disease therapies: a scoping review. Semin Arthritis Rheum. 2020; 50:1191-201.

https://doi.org/10.1016/i.semarthrit.2020.07.007

PMID:32931985 